\title{
Creating Diversity in Tomorrow's Doctors: A Student Led, Widening Participation Outreach Programme
}

\section{Gabrielle Sanders (D) \\ Connor Brett (D) \\ Nadine Paul $\mathbb{D}$ \\ Jessica Scott $\mathbb{D}$}

Faculty of Life Sciences and Medicine, King's College London School of Medical Education, London, SEI IUL, UK

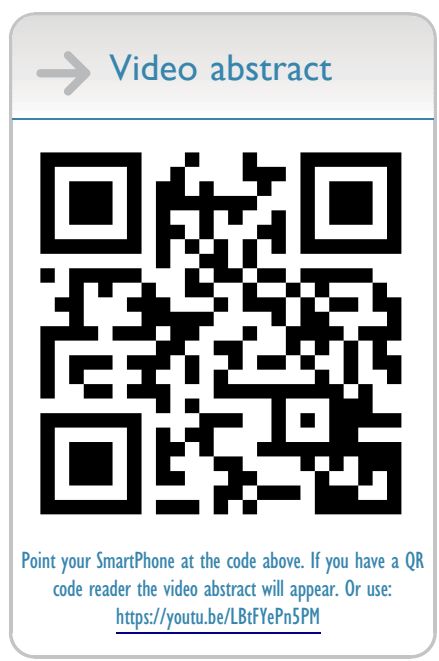

Correspondence: Gabrielle Sanders Faculty of Life Sciences \& Medicine, King's College London School of Medical Education, London, SEI IUL, United Kingdom

Tel +4479/3348847

Email gabriellesanders0I@gmail.com

\begin{abstract}
Since its founding in 2017, InsideMed, an entirely voluntary medical student led innovation, has offered local London state school students a unique perspective exploring the application process and realities of a career in medicine. Our aim of promoting diversity and widening participation (WP) amongst future medical school applicants is reflected in the fact $80.2 \%$ of the students enrolled are from Black Asian and Minority Ethnic groups (BAME). Over an 18 month period, our students are invited to monthly seminars hosted at King's College London (KCL), where all things "medical school" are explored. Students are paired with current KCL medical student ambassadors and are grouped into 'Families'. Between sessions, students and ambassadors are facilitated to communicate freely, but safely through the online platform Brightside. Early establishment of our key stakeholders allowed us to anticipate how InsideMed would impact each in turn and, therefore, design our scheme to ensure maximal mutual benefit. Continual feedback and review ensures that we are constantly improving to meet the needs of our students. Feedback also allows us to identify how closely we have served our aims for each cohort; common themes which consistently arise include the creation of community, learning more about specifics of the medical application process, and building self-confidence and student independence. InsideMed has the unique quality of being designed by WP students and constantly updated to ensure the support provided best meets WP needs. This has fed into our tangible and impressive impact, whereby 7 out of 18 respondents from our 2017 cohort of students have been accepted into medical school. Going forward, we hope to expand our scope to include a wider catchment area and will continue online in the COVID era. We aim to create an expansive alumni community to inspire other students from comparable socioeconomic backgrounds that they too can have a career in medicine.
\end{abstract}

Keywords: widening participation, peer-to-peer learning, outreach, year 12 students

\section{Background}

Widening Participation (WP) has a special relevance to the Medical Profession. The British Medical Association (BMA) advocates that "doctors should be as representative as possible of the society they serve in order to provide the best possible care to the UK population". ${ }^{1}$ But, throughout history, medicine has been a career for the most privileged. Approximately eight applicants compete for a single place and only $4.1 \%$ of entrants are from a WP background. ${ }^{2,3}$ While progress has been made with regards to gender, ethnicity and age of medical students, socioeconomic background lags behind. ${ }^{1}$ The UK Medical School Council highlights that $80 \%$ of medical students studied at only $20 \%$ 
of the UK's schools. ${ }^{4}$ The aetiology is multifaceted; WP students underestimate their potential, lack identifiable role models and have unequal accessibility to resources and social capital. ${ }^{5}$ UK universities have increasingly sought to promote WP within their medical schools, with the aspiration of ensuring the NHS is reflective and understanding of its future patients' needs.

One flagship programme created to promote diversity and equality in medicine is the six-year Extended Medical Degree Programme (EMDP), offered by King's College London (KCL). ${ }^{6}$ It enables students with academic potential, who may not have achieved the A-level grades required by conventional medical degree programmes, to study medicine.

InsideMed was founded by four students of the EMDP Society committee in 2017 (see acknowledgements), to guide aspiring medical students from WP backgrounds through the university application preparatory process.

\section{Aims}

InsideMed aims to encourage those with the potential to study medicine to regard it as a viable option, irrespective of their socio-economic circumstances. Hence the scheme remains free to access, enabled by the voluntary efforts of our ambassadors and committee members.

Longer term, we will continue to build a community of InsideMed alumni who promote equal opportunities and inspire those from disadvantaged socio-economic backgrounds, widening access to higher education.

\section{Methods}

\section{The Team}

The InsideMed team is made up of six key players. Complete role descriptions are in Appendix A. We have a flat hierarchy where decision making is collaborative between all team members.

\section{Stakeholder Analysis}

When introducing change, it is important to conduct a thorough stakeholder analysis to reduce conflict and delay caused by the failure of involving key people. ${ }^{7}$ The founding team identified InsideMed's immediate and broader stakeholders (Figure 1), liaised with them to understand their opinions on introducing a near peer support scheme, and subsequently strategized how we could create thriving partnerships to ensure InsideMed's growth and sustainability (for further details see Appendix B).

\section{The Application Process}

Students in year 12 from the London Boroughs of Lambeth and Southwark were invited to apply to the programme. The inclusion criteria included studying at a non-selective (state) school and having achieved the

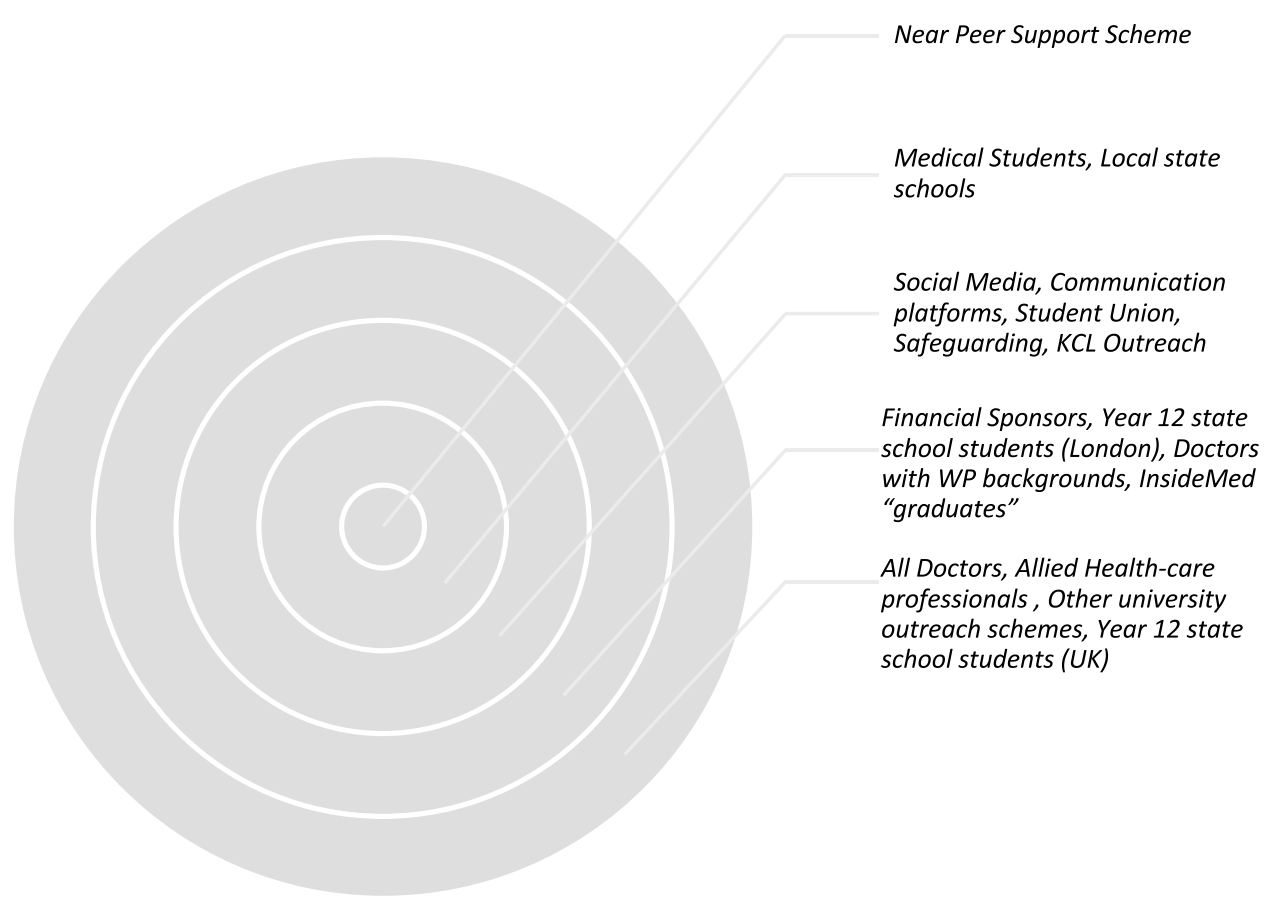

Figure I Stakeholder map illustrating the immediate, narrow and broad stakeholders of a near peer support scheme for Year 12 aspiring medical students, based on the Stakeholder theory. ${ }^{8}$ 
Table I Table Illustrating Year 12 Student Demographics in Each Cohort

\begin{tabular}{|l|r|r|r|}
\hline & 2017-18 & 2018-19 & 2019-20 \\
\hline Number of students & 24 & 31 & 31 \\
\hline Gender & $8 \mathrm{M} 16 \mathrm{~F}$ & $5 \mathrm{M} 26 \mathrm{~F}$ & $6 \mathrm{M} \mathrm{25F}$ \\
\hline BAME ethnic group & 19 & 28 & 22 \\
\hline $\begin{array}{l}\text { First generation to attend } \\
\text { university }\end{array}$ & 17 & 18 & 20 \\
\hline
\end{tabular}

minimum GCSE grades required for entry into the King's EMDP programme. Over the years we have welcomed other nearby boroughs including Ealing, Greenwich, Newham, Brent, Hackney and Westminster. Students are asked about their motivations to study medicine, and what they would gain from the InsideMed programme. Students who are the first generation in their family to attend university were also prioritised. A standardised application process was implemented to ensure ambassadors and year 12 students remain engaged throughout the scheme and prioritise those who will most benefit. (Please see details in Appendix C). The resultant Year 12 demographic profile per cohort can be seen in Table 1 .

\section{Core Activities}

Approximately 30 year 12 students and a complimentary number of medical students are recruited to enable a 2:1 ratio. Two of these pairings are merged to form a "family" of six, facilitating deeper discussion. Face-to-face sessions run monthly, for 90 minutes, on Guy's Campus, covering various aspects of the application process (see timetable in Table 2). We also host practical sessions including a doctor networking event, clinical skills workshop, and study skills session.

Outreach officers introduce topics through 20 minute presentations. The group then disperse into their "families" for 60 minutes of ambassador guided discussion. The final 10 minutes involve a whole group debriefing, facilitated by the outreach officers. This encourages inter-family rapport, distribution of knowledge and highlighting of key messages.

Our ambassadors do not receive any formal training, besides a safeguarding session and a Disclosure and Barring Service (DBS) check. The objective is for ambassadors to follow the course of conversation and act as participants in the discussion, avoiding any tendency to
Table 2 Template Used to Structure Each Year

\begin{tabular}{|l|c|}
\hline Month & Session \\
\hline Oct & $\begin{array}{r}\text { Medical Student Ambassador safeguarding training and } \\
\text { Introductions with Committee } \\
\text { Year I2 Student Introductions with Committee } \\
\text { Brightside introductions with Year I2 Students and Student } \\
\text { Ambassadors }\end{array}$ \\
1) Overview of medicine and Goal setting (whole family)
\end{tabular}

lecture. This Socratic method of teaching allows students values and beliefs to be explored. ${ }^{9}$ However, we do provide ambassadors with guidelines to ensure consistency and quality of teaching across families.

Outside sessions, communication with ambassadors is enabled through Brightside, an online mentoring platform that puts young people in touch with mentors who can share their knowledge and experience with them to guide their education and career options. ${ }^{10}$ Messaging via the platform is moderated by Brightside staff and nominated members of committee for safeguarding.

The use of feedback forms has evolved since our beginnings. Initially, we collected feedback at baseline and after our final session. Since our second year, we have distributed feedback forms after every session. These have also evolved from a single likert scale ranking the session out of 5 and asking for views on what went well and what could be improved. Since our third year, we have used a series of likert scales measuring various parameters: quantifying improvements in their understanding of the topic, quality of the resources provided, and usefulness for the future, in 
addition to open-ended questions for students to expand on their views. We also host a reflective writing competition, implemented in our second year of running, for graduating students to reflect on their InsideMed experience, emulating the length and style of a personal statement, and allows us to collect more detailed qualitative feedback.

Qualitative feedback was analysed using the Braun and Clarke six step approach to thematic analysis ${ }^{11}$. The beginning of the data organization process involved exporting participants' responses for each question into an excel spreadsheet and then creating codes, which are a description of the content of each response. The same codes were then collated together and similar codes were grouped to form common themes. Themes were then refined by reviewing the content under each code. A visual thematic map was used to clarify patterns and ensure themes were distinct from one another.

We do not arrange formal face-to-face sessions for our year 13 alumni. Brightside, however, remains open and we host voluntary on-campus personal statement clinics and a mock Multi Mini Interview (MMI) circuit.

\section{Results}

Qualitative feedback from all three InsideMed cohorts, totalling ninety Year 12 students, have been aggregated (summarised in Figure 2).

The first theme is community. Students liked being matched with their own medical student role model for

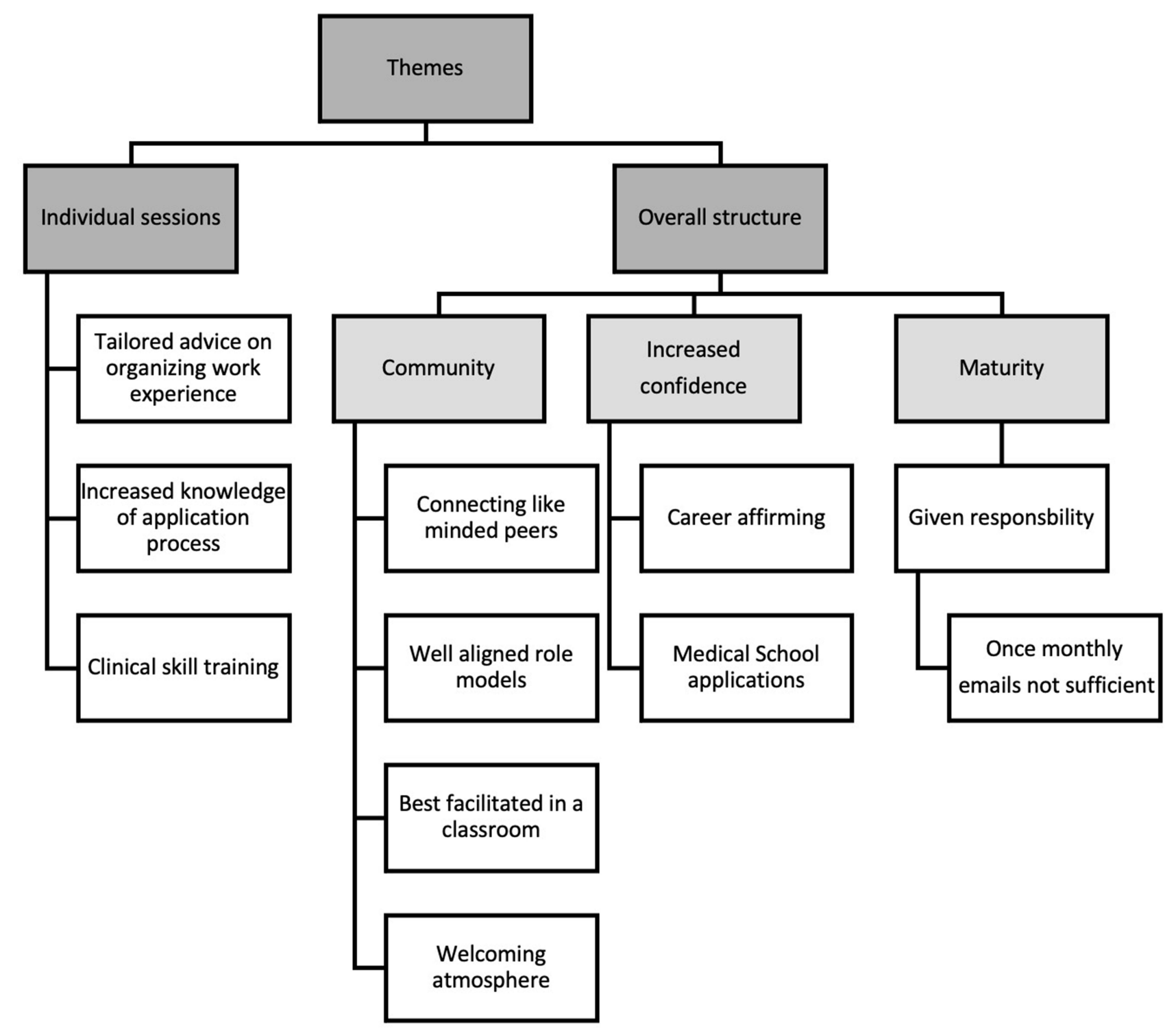

Figure 2 Thematic analysis extracted from end of year feedback surveys and Year 12 reflective essays across three years of InsideMed. 
two years because advice was tailored to their personal circumstances. They found comfort in their role model being of similar age. Students also appreciated being connected with other year 12 students with comparable goals and barriers to accessing the medical profession, to share advice and concerns. Direct student quotes are shown in Figure 3a.
Another prevalent theme was increasing student confidence. Through sharing insight into the role of a doctor, students felt they could make an informed decision about entering the career. Some students noticed maturation of their own character through newfound independence; managing emails, independently commuting to sessions and realising the benefits of punctuality. Specific sessions

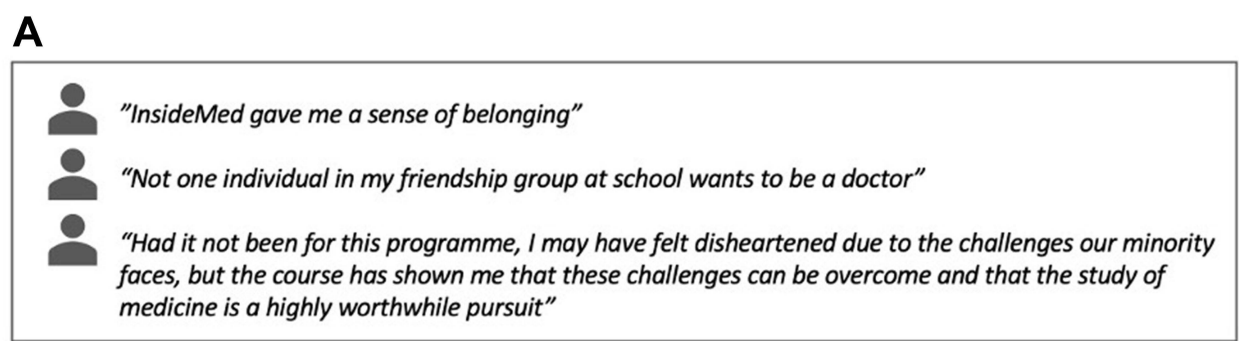

B

"Overall the programme has changed my perception of the medicine application process and given
me the tools and confidence to pursue medicine as a career which is something that I did not have
before the programme, so thank you"
"Before InsideMed, I had never travelled alone to Central London and this was a big milestone for me.
Ialso developed my time management skills which are a large part of studying medicine and being a
doctor and for that, I am truly grateful. It goes to show that what I gained from this experience was
much greater than just sitting in lecture halls and taking down notes. It was interactive and took me
out of my comfort zone thus instilling confidence in myself"
"The improvement in my organisation has enabled me to run and be elected as president of the
Student Union at my sixth form"

Figure 3 (A) Student quotes on community. (B) Student quotes on confidence.

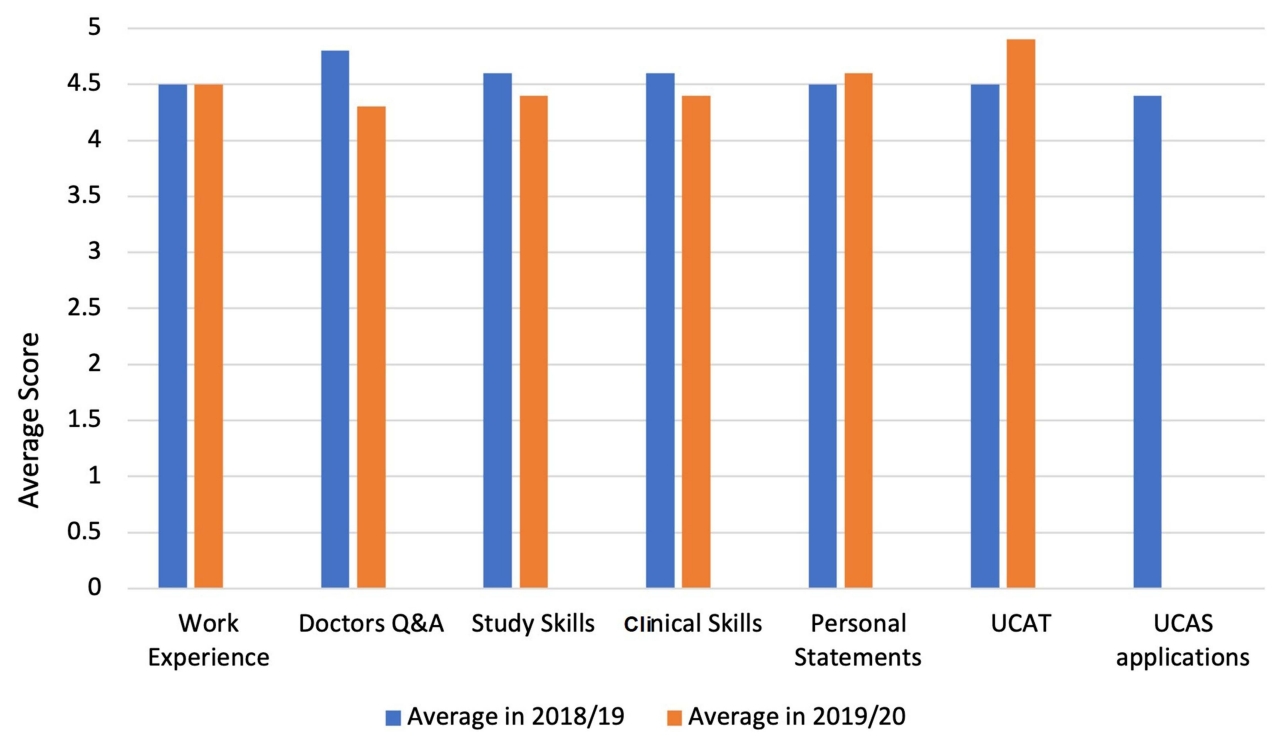

Figure 4 Average score from likert Scales for individual sessions in cohorts 2018/19 and 2019/20. The UCAS applications session was not run in 20I9/20 due to logistical issues with carrying out the session online and acquiring sufficient mentor volunteers. 
were also delivered to improve organisational skills, such as "Goal Setting" and "Study Skills" (see Figure 3b).

Across the cohorts where we collected individual session feedback, every session was reported relevant; the lowest average rating totalled 4.3 out of 5 . The most valued sessions varied between cohorts (see Figure 4).

Students from the 2019/20 cohort provided insight into the scores they gave for each session via more specific feedback. The high quality of resources provided was commented on by many students, particularly in response to the UCAT session. Students found the resources useful for practicing UCAT style questions. This helped improve their understanding and was a large contributing factor to the high session score overall. Many students commented that their understanding of the topics covered was improved by the sessions. This was particularly pertinent in the personal statement session where several students stated that they did not have much prior knowledge but felt more confident after the session. The clinical skills session proved popular with both cohorts. The 2019/20 cohort found this session particularly useful for the future, as they developed skills they will use throughout their careers. All sessions ranked highly over both cohorts, therefore it is difficult to differentiate the sessions the students benefited from the most. In future we will ask students to rank the sessions out of 10 to gain more granularity on how useful students found each session.

InsideMed continually evolves in response to feedback. In our first year, students reported difficulty in organising work experience, therefore the summer work experience scheme was introduced the following year, involving two and a half days of observational clinical placement. The session students least enjoyed was the study skills session; the lecture theatre and lack of student ambassadors was reported to create an intimidating and less interactive environment. We now host this session in a classroom, using case studies to allow students to reflect on their own study habits.

A follow-up survey with the 2017 InsideMed "graduates" was conducted in March 2020. Of the 18 respondents, ten had received and accepted a university place. Of these, seven were studying medicine at universities including Southampton, King's College, Nottingham, and Cambridge. The remainder were studying biomedical sciences.

\section{Discussion}

The most unique aspect of InsideMed is the length and continuity of the program. Students have face-to-face support throughout year 12, followed by support online and two optional workshops in year 13. This enables continuity for the students as they have several points of contact and support from a wider community throughout the fairly complex medical application process. Although $\mathrm{KCL}$ Outreach for Medicine organise many useful outreach courses, ${ }^{12,13}$ we felt, in order to truly disrupt the demographics of the workforce, we must instil confidence in the future generation of doctors to challenge the social norms they are accustomed to. Year 12 students preparing their applications face a series of stressful hurdles. Breaking these down in monthly sessions equips students with the skills to overcome them. Furthermore, inviting students to the medical campus and hosting sessions in university lecture theatres allows them to step into the shoes of a medical student, and is unlike many other initiatives where ambassadors visit students at their secondary school. $^{14}$

In total, $80.2 \%$ of the students enrolled on InsideMed are from Black Asian and Minority Ethnic groups (BAME), compared to the $35.5 \%$ who are accepted into medical school in the UK. ${ }^{15}$ Since our selection process removes the typical barriers into higher education we have been able to create a significantly different balance of ethnicities compared to the national average working in the NHS, which currently stands at $22.1 \%{ }^{16}$. However, we do acknowledge our sample size is small and specific to a handful of London boroughs; ethnic diversity will vary depending on the demographics of the local community, and may not be generalisable for schemes operating at a larger scale.

InsideMed is an entirely medical student-led scheme, offering the advantage of aligning with medical students' busy timetables and is more informal than faculty-led and university-wide initiatives. However, we advise new near peer schemes to state the minimum number of hours expected of ambassadors to spend at sessions and online. Despite our fairly rigorous application process, some ambassadors found the expectations of InsideMed to be more than they could commit to. This resulted in a small attrition of ambassadors, but significantly affected the partnered year 12 students who felt frustrated and let down. 
Brightside was essential in enabling continued delivery through the COVID-19 pandemic. Despite the fact it is less personal and interactive than usual face-to-face sessions, it allowed ambassadors to provide continued support remotely.

\section{Conclusions}

We believe the success of InsideMed is largely due to understanding our target audience and the macro environment we operate within. The co-founders and many of our voluntary ambassadors are from WP backgrounds, and so are able to understand the challenges of our students, having had similar journeys themselves. Initial thorough stakeholder analysis allowed us to identify all avenues of support to offer students, and we have learnt that collecting regular feedback allows us to identify what students want and how to continually improve, and therefore generate a meaningful impact.

We hope this article provides medical students from other universities with the motivation and template to create their own WP scheme, to achieve our ultimate aim of providing more students with equal opportunities. Looking forward, we plan to expand our geographical scope to include more London Boroughs, within the confines of sustaining our community atmosphere.

Our template may be adapted to widen access for other demographics, including postgraduate students who would benefit from the experiences of those who have successfully accessed medical school via this route. We would particularly like to highlight the value of long-term online mentoring, should the organisation of room bookings and engagement with all key stakeholders necessary to set up an in-person scheme be challenging.

\section{Abbreviations}

BAME, Black Asian and Minority Ethnic groups; BMA, British Medical Association; EMDP, Extended Medical Degree Programme; KCL, King's College London; MMI, Multi Mini Interview; WP, Widening Participation; UCAT, University Clinical Aptitude Test.

\section{Ethics Approval}

The student feedback collected during this innovation was not designed to be research, but to be a form of peer review to ensure support provided met the needs of our students in the future. In order to decide if our analysis required ethics approval, we used the Medical Research Council's decision tool. The outcome of this was that our project would not be considered research, and therefore we did not seek ethical approval. ${ }^{17}$ However, an opening statement at the top of all of our questionnaires informed respondents that their feedback would remain anonymous and used for the continual improvement of our processes. Furthermore, the information gathered has been published as overarching themes, meaning individuals are not identifiable and sensitive information has not been disclosed.

\section{Acknowledgments}

We would like to thank Sajeel Din, Oluwatobi Esan and Marwah Salih, who with Gabrielle Sanders, are Co-founders of the InsideMed Scheme. Additionally, we'd like to thank the past committee members Precila Fernandes Da Costa, Olayinka Deborah Amire and Alexandra Sanyaolu, who ensured the smooth daily running of the scheme, alongside all medical student ambassadors who gave up their spare time to carry out the initiative.

We are also grateful for all the support we have received from KCL Outreach for Medicine Department, specifically Michaela O'connell and Katharine Morgan. Thank you for the invaluable guidance on how to best aid our students. And also to Anisha Bhogaita who ensured we were all properly trained with regards to safeguarding, and well equipped to run the scheme. And thank you to Dr Jane Valentine for your support from the inception of InsideMed, and allowing us to host our students at the Extended Medical Degree Porgramme's awards evening for academic excellence, to recognise their hard work. We would also like to wholeheartedly thank Dr. Ann Mckee for her guidance on medical education techniques.

And finally we would like to thank everyone at Brightside, whose platform was invaluable for the scheme to run and ensure smooth communication between the scheme organisers and the students. We greatly appreciate all the financial support the scheme has received over the years from KCLSU Widening Participation fund, Kaplan and DreamSmart tutors.

This was an entirely voluntary scheme led by medical students from WP backgrounds who wanted to help more students like them get into medical school. The scheme was entirely free for Year 12 students. Miss Gabrielle Sanders affirms that students enrolled onto the InsideMed programme were not favoured in the King's Medical School application process, and were made aware from the outset that InsideMed was created and led by a student 
society at Kings College London, and a separate entity from the medical school admissions team. They were informed that any feedback they provided us (positive or negative) was for the purpose of improving InsideMed, and in no way affected their future prospects of being accepted into medical school. All data used in the creation of this figure is original, collected by the authors and constructed for the purpose of this publication and has not been published elsewhere previously.

\section{Disclosure}

The authors report no conflicts of interest in this work.

\section{References}

1. Equal Opportunities Committee. Equality and diversity in UK medical Schools [Internet]; 2009. [cited 21 August 2020]. Available from: http://www.hscbusiness.hscni.net/pdf/BMA-Equality_and_Diversity_ in_UK_Med_Schools_2009_pdf.pdf. Accessed Jun 9, 2021.Equality

2. Ul-Hassan A, Khanom S, Sucharitkul P, Jones CM, Waduud MA. Twelve tips for applicants from a disadvantaged background considering a career in medicine. MedEdPublish. 2019;8.

3. Jones-Berry S. The Right Mix | british Medical Association [Internet]. Questionnaires.bma.org.uk; 2015. [cited August 21, 2020]. Available from: https://questionnaires.bma.org.uk/news/therightmix/index.html. Accessed Jun 9, 2021

4. Medical Schools Council. Selecting for Excellence Final Report [Internet]. 2014. [cited 16 June, 2021]. Available from: https://www. medschools.ac.uk/media/1203/selecting-for-excellence-final-report. pdf.

5. Greenhalgh T, Seyan K, Boynton P. "Not a university type": focus group study of social class, ethnic, and sex differences in school pupils' perceptions about medical school. BMJ. 2004;328 (7455):1541. doi:10.1136/bmj.328.7455.1541

6. King's College London. Extended Medical Degree Programme | study at King's [Internet]. Kcl.ac.uk; 2020. [cited 21 August 2020]. Available from: https://www.kcl.ac.uk/study/undergraduate/courses/ extended-medical-degree-programme-mbbs. Accessed Jun 9, 2021
7. NHS England and NHS Improvement. Stakeholder Analysis. Available from: https:/www.england.nhs.uk/wp-content/ uploads/2021/03/qsir-stakeholder-analysis.pdf . Accessed Jun 9, 2021

8. Freeman RE, Harrison JS, Wicks AC. Managing for Stakeholders: Survival, Reputation, and Success. Yale University Press; 2007.

9. George L. Socrates on Teaching: looking Back to Move Education Forward. Procedia. Social Behav Sci. 2015;174:3970-3974.

10. Brightside [Internet]. Brightsidementoring.org; 2020. [cited 21 August 2020]. Available from: https://brightsidementoring.org/. Accessed Jun 9, 2021

11. Braun V, Clarke V. Using thematic analysis in psychology. Qualitative Res Psychol. 2006;3(2):77-101. doi:10.1191/ 1478088706qp063oa

12. King's College London About Outreach for Medicine [Internet]. Kcl. ac.uk; 2020. [cited 21 August 2020]. Available from: https://www. kcl.ac.uk/lsm/study/outreach/about/index. Accessed Jun 9, 2021

13. What is $\mathrm{K}+$ ? | study at King's | king's College London [Internet].Kcl. ac.uk; 2020. [cited 21 August 2020]. https://www.kcl.ac.uk/study/ widening-participation/our-activities/k-plus. Accessed Jun 9, 2021

14. Ryan B, Kitchen A, Chan A, Gibson H, Haque E. Widening participation to medicine: a student-led workshop for medical school applicants. MedEdPublish. 2018;7.

15. Advance HE Students statistical report 2018 [Internet]. Equality+ higher education; 2018. [cited 21 August 2020]. Available from: https://www.advance-he.ac.uk/sites/default/files/2019-05/2018-06ECU_HE-stats-report_students_v5-compressed.pdf. Accessed Jun 9, 2021

16. Gov.uk. NHS workforce [Internet]. Ethnicity-facts-figures.service. gov.uk; 2019. [cited 21 August 2020]. Available from: https://www. ethnicity-facts-figures.service.gov.uk/workforce-and-business/work force-diversity/nhs-workforce/latest\#by-ethnicity. Accessed Jun 9, 2021

17. Medical Research Council. Is my study research? [Internet]. Hradecisiontools.org.uk; 2021. [cited 19 February 2021]. Available from: http://www.hra-decisiontools.org.uk/research/about.html. Accessed Jun 9, 2021
Advances in Medical Education and Practice

\section{Publish your work in this journal}

Advances in Medical Education and Practice is an international, peerreviewed, open access journal that aims to present and publish research on Medical Education covering medical, dental, nursing and allied health care professional education. The journal covers undergraduate education, postgraduate training and continuing medical education

\section{Dovepress}

including emerging trends and innovative models linking education, research, and health care services. The manuscript management system is completely online and includes a very quick and fair peer-review system. Visit http://www.dovepress.com/testimonials.php to read real quotes from published authors. 